\title{
Chest Necrotizing Fasciitis with Mediastinitis
}

\author{
Atsushi Ohsaki, Fumitaka Shirasaki and Nobutaka Hirooka
}

Key words: crepitus, subcutaneous emphysema, necrotizing fasciitis, mediastinitis

(Intern Med 56: 1755-1756, 2017)

(DOI: 10.2169/internalmedicine.56.8373)

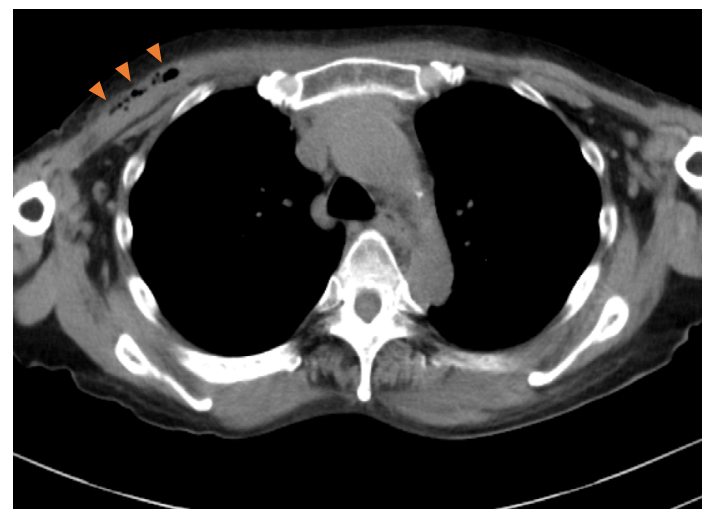

Picture 1.

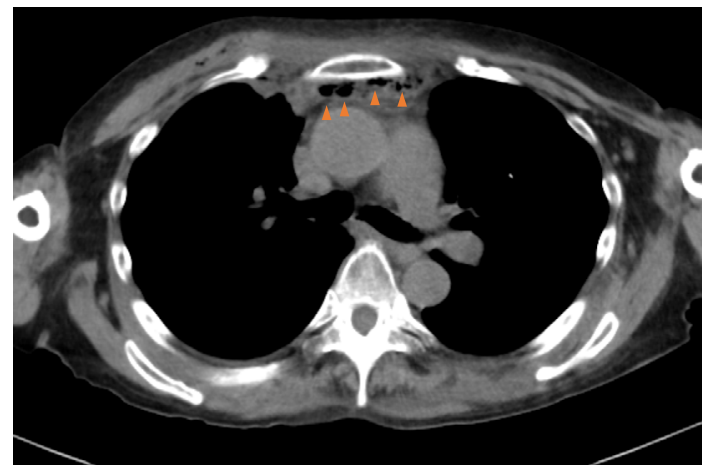

Picture 3.

A 54-year-old woman with a history of psoriasis, which had been treated with methotrexate, and poorly-controlled diabetes (HbA1c $9.8 \%$ ) presented with anterior chest pain. She initially developed mild pain in the right upper-anterior chest. The patient was immediately referred to our hospital after the symptoms extended to the anterior chest wall and neck at 10 days after the onset of symptoms. Examinations showed crepitus and severe tenderness of the right to mid chest. While afebrile, a low blood pressure and tachycardia

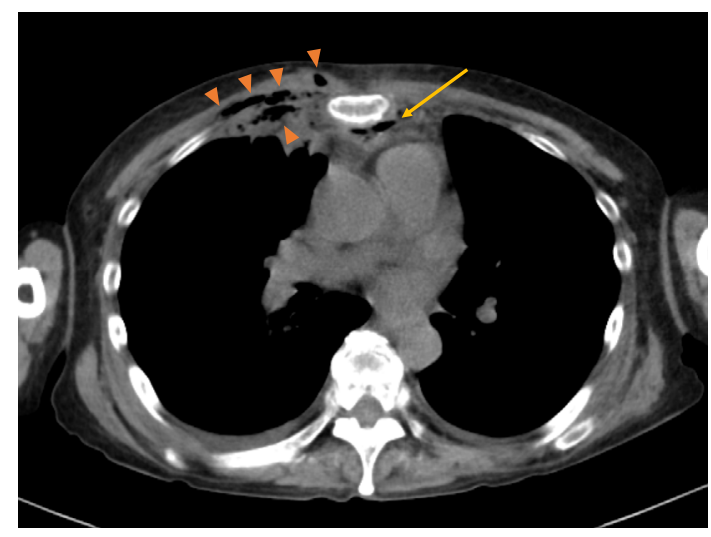

Picture 2.

were also present. Chest CT (Picture 1-3) showed subcutaneous emphysema due to necrotizing fasciitis, which extended to the mediastinum. The diagnosis was confirmed by thoracotomy and debridement, which stabilized the condition enough to allow ambulatory rehabilitation by the $23 \mathrm{rd}$ of the hospital day. Despite the fact that the patient had no history of recent hospitalization, cultures of the necrotic tissue detected methicillin-resistant Staphylococcus aureus. Chest fasciitis causing mediastinitis is an extremely rare and significant comorbidity of diabetes $(1,2)$. The patient had poorly controlled diabetes and was undergoing immunosuppressant treatment, both of which are risk factors for this life-threatening disease.

The authors state that they have no Conflict of Interest (COI).

\section{References}

1. Zaki M, Akhtar M, Saxenda D, Kundra DN, Murtuza R. Necrotizing faciitis of anterior chest wall and neck. Pak J Med Sci 3: 3233, 2013.

2. Elander J, Nekludov M, Larsson A, Nordlander B, Eksborg S, Hydman J. Cervical necrotizing fasciitis: descriptive, retrospective analysis of 59 cases treated at a single center. Eur Arch Otorhino-

Department of General Internal Medicine, Saitama Medical University, Japan

Received for publication October 6, 2016; Accepted for publication November 1, 2016

Correspondence to Dr. Nobutaka Hirooka, nkaorohi@saitama-med.ac.jp 
Intern Med 56: 1755-1756, 2017 DOI: 10.2169/internalmedicine.56.8373

laryngol 273: 4461-4467, 2016.

The Internal Medicine is an Open Access article distributed under the Creative
Commons Attribution-NonCommercial-NoDerivatives 4.0 International License. To view the details of this license, please visit (https://creativecommons.org/licenses/ by-nc-nd/4.0/).

(C) 2017 The Japanese Society of Internal Medicine http://www.naika.or.jp/imonline/index.html 